\title{
EL CORÁN ROMANCEADO: LA TRADUCCIÓN CONTENIDA EN EL MANUSCRITO T 235
}

\author{
Consuelo López-Morillas \\ Indiana University
}

\section{INTRODUCCIÓN}

El manuscrito 235 de Toledo (antes conservado en la Biblioteca Pública Provincial, hoy en la de Castilla-La Mancha) contiene una traducción completa del Corán del árabe al español, copiada en 1606 en letra latina por un morisco anónimo. Varios estudios anteriores han establecido la importancia y el interés de esta obra, ${ }^{1}$ cuya edición estoy actualmente ultimando. Aprovechando la ocasión de este homenaje a L. P. Harvey, a quien, al igual que otros aljamiadistas, tanto debo personalmente, me prop ongo adelantar parte del estudio que acomp añará a esa edición. Se trata de un análisis de la traducción misma y de las técnicas empleadas por el traductor, investigación que, espero, ilumine las circunstancias en que se produjo un texto que constituyó un proy ecto pionero en la historia del Islam español.

Recordemos escuetamente algunos datos fundamentales (para más detalles, véanse los estudios citados en la nota 1). El morisco que copió el ms. 235 anota que trabajó entre abril y julio

1. Ver E. SAAVEDRA, “ Índice general de la literatura aljamiada”, apéndice al Discurso leído ante la Real Academia Española (Madrid, 1878), nº. LVI, p. 277 (reimpr. en Memorias de la Real Academia Española, 6 [1889], pp. 140-328); cuatro estudios por C. LÓPEZ- Morillas: The Qur’ān in Sixteenth-Century Spain: Six Morisco Versions of Süra 79 (Londres: Tamesis, 1982), p. 20 et passim, “'Trilingual' Marginal Notes (Arabic, Aljamiado, and Spanish) in a Morisco Manscript from Toledo”, Journal of the American Oriental Society, 103 (1983), pp. 495-504, “Lost and Found? Yça of Segovia and the Qur’ān Among the Mudejars and Moriscos”, Journal of Islamic Studies, 10 (1999), pp. 277-92, y “La autoría del manuscrito coránico morisco T235”, Escritura, individuo y sociedad en España y en las Américas. Homenaje a Luce López-Baralt y Mercedes López-Baralt (San Juan: Universidad de Puerto Rico), en prensa; y G. WIEGERS, Islamic Literature in Spanish and Aljamiado: Yça of Segovia (fl. 1450), His Antecedents and Successors (Leiden: Brill, 1994), p. 15 et passim. Falta en A. GonzÁlez P ALENCiA, “Noticia y extractos de algunos manuscritos árabes y aljamiado de Toledo y Madrid”, Miscelánea de estudios y textos árabes (Madrid: Centro de Estudios Históricos, 1915). 
de 1606, pero no hace constar ni su nombre ni su lugar de origen. Nos informa que copió el texto con toda fidelidad de un original que le había sido prestado. Este original contenía tanto el texto árabe del Corán como la traducción española, escrita en caracteres árabes (es decir, en aljamiado). El amanuense, por falta de tiempo, suprimió el Corán árabe y reprodujo solamente la parte romanceada, vertiéndola al mismo tiempo al alfabeto latino por considerar que éste sería más comprensible para sus correligionarios.

Este mismo copista es el responsable de otros dos mss.: el 232 de la misma biblioteca de Toledo, y el S-1 de la Real Academia de la Historia. Unos apuntes que dejó en el ms. 232 me sugieren que el cop ista pudo ser el morisco Muhammad Rubio de Villafeliche (Zaragoza), a quien encontramos en el exilio en Túnez dos o tres décadas después. El ms. 235, que nunca llegó a salir de la Península, acabó en la colección toledana tal vez por donación de una rama de los Borbones.

Siendo este ms. 235 de 1606 una mera copia de una traducción del Corán, se presenta la cuestión de quién realizó esa traducción original. G. Wiegers ha propuesto como traductor original al distinguido mudéjar 'Īsā ibn Ŷābir o Yça Gidelli, alfaquí de Segovia en el siglo XV, puesto que en efecto se sabe que Yça, patrocinado por Juan de Segovia, tradujo el Corán al español en 1456. Aunque esta versión se consideraba perdida, existe sobre ella amplia información contenida en un prólogo latino que Juan de Segovia preparó para la obra. Sabemos, por ejemplo, que Yça hizo la traducción en Aiton, en Saboya; que consultó durante su trabajo libros escritos en árabe; y que dejó una copia en Aiton con Juan (quien la tradujo a su vez al latín) pero se trajo otra copia consigo al volver a España. El prólogo de Juan, además de contar estas circunstancias externas del proyecto, proporciona algunas citas de la versión latina y otros detalles sobre la versión española que indican un parecido significativo entre lo que fuera la traducción de Yça y el texto del ms. 235.

Creo ahora que la identificación del 235 con la traducción de Yça Gidelli es altamente probable, aunque, en el estado actual de nuestros conocimientos, no es segura. No sé de ninguna pista concreta sobre este texto durante el siglo y medio de 1456 a 1606. Durante ese intervalo la versión de Yça tuvo que pasar de Castilla a Aragón, puesto que el ms. 235 es aragonés tanto en su procedencia como en su lenguaje. La letra de la traducción original, supuestamente latina, debió convertirse en algún momento en árabe, pues el amanuense de 1606 copió de un manuscrito aljamiado; sin embargo, ninguna versión aljamiada del Corán de época morisca -al menos ninguna que se conserve- contiene el mismo text o que el 235. Yça Gidelli era la mayor autoridad de la Península en materia islámica y nos han llegado varias obras suy as, alguna en varios manuscritos. Es tal vez una ironía que el libro que bien pudo ser su magnum opus, su traducción del Corán al castellano -la primera de la historia- desapareciera t otalmente durante 150 años sin, al parecer, inspirar ninguna copia ni imitación. Con todo, Yça es el autor más plausible de la versión 
del Corán contenida en el ms. 235. A lo largo del análisis me refiero a él sólo como "el traductor”, pero en la Conclusión discutiré la evidencia concreta que nos permite sosp echar que el traductor fue Yça Gidelli. ${ }^{2}$

Siendo el presente artículo un solo cap ítulo de un estudio de may or envergadura, no pretendo solucionar todos los problemas del manuscrito sino que desarrollaré muchos aspectos en la edición futura. Pero quiero adelantar aquí una conclusión importante: que la influencia de la exégesis árabe sobre el texto es más extensa de lo que se pensaba. Esta versión española, lejos de ser una traducción "pura" de las palabras del Corán, incorpora ex silentio muchas interpretaciones extracoránicas sacadas de los comentaristas. Por lo tanto, añade nuevos datos a la historia del tafsīr en el Islam esp añol.

\section{PROCEDIMIENTO}

Para apreciar en su medida justa la labor realizada por el traductor de este texto sagrado, me pareció imprescindible comparar minuciosamente la versión española con el original árabe del Corán. Si estamos, de hecho, ante el primer intento de traducir la escritura musulmana -ante la versión de Yça, del siglo XV-, hay que suponer que el traductor trabajó sin tener ningún modelo previo ante sus ojos. Se guiaría en parte por la consulta de obras de tafsīr, pero habría tenido que valerse, mayormente, de sus propios conocimientos del árabe y del castellano. La empresa que se propuso fue ambiciosa y difícil, y no debemos juzgar el resultado con excesiva severidad. Aunque el traductor cometió numerosos deslices, el balance de su esfuerzo es sin duda una traducción fiel tanto a la letra como al espíritu del texto original.

No debe sorprendernos que la versión española sea altamente literal. El traductor siguió muy de cerca el texto árabe y las más de las veces tradujo casi palabra por palabra, produciendo giros gramaticales y sintácticos más típicos de la fraseología semítica que de la románica. A veces el

2. Cabe mencionar aquí que Juan Andrés, el converso autor de la Confusion dela secta mahomatica y del alcoran (Valencia, 1515), dice haber traducido “ $\mathrm{d}[\mathrm{e}]$ arauigo en le[n]gua aragonesa... el alcoran con sus glosas” a partir de 1504. Esta supuesta traducción, igualmente des aparecida, no parece que pueda identificarse con el ms. 235 , a juzgar por los títulos de las azoras que cita Juan en la Confusion. Si las comparamos con los títulos de nuestro manuscrito, encontramos muchas diferencias: $n^{\circ}$. 3, en Juan Andrés “la familia de joachim padre de nuestra señora” y en 235 “Éli Ymran”; n. 6, en Juan “los ganados” y en 235 “Los aberios”; n. 7, en Juan “el muro” y en 235 “al @raf”, y así sucesivamente (de los 51 títulos comparables, sólo 17 o el 33,3\% concuerdan). No he tenido acceso a la Confusion, sino que cito de H. BoBzin, “ Bemerkungen zu Juan Andrés und zu seinem Buch Confusion dela secta mahomatica (Valencia 1515)”, en M. Forstner (ed.), Festgabe für Hans-Rudolf Singer (Frankfurt am Main: Peter Lang, 1991), pp. 529-548, esp. pp. 544-547. 
resultado es algo absurdo: el afán de no omitir nada puede producir secuencias como "aquello fue porque ello es que era que” ([318 v]: dălika bi-annahu kānat, 64:6). Se trata de una lengua calco: es el procedimiento archiconocido utilizado p or, entre otros, los traductores del Pentateuco al ladino. ${ }^{3} \mathrm{Si}$ en las traducciones modernas, sean de textos religiosos o seglares, tal grado de literalismo se considera un defecto, aquí ocurre todo lo contrario. Es el deber del traductor no alejarse demasiado del original, para que su versión conserve el carácter sagrado del mismo. Por lo tanto, no hago hincapié en muchos fenómenos que son perfectamente explicables por este excesivo ap ego al lenguaje coránico. A decir verdad, tales giros no iluminan otra cosa que lo bien que el traductor comprendía el texto que tenía delante. Lo realmente revelador, en cambio, son los casos en que no se traduce con fidelidad literal, casos que nos permiten especular sobre el motivo del tropiezo: ¿ignorancia, descuido, tabú, otras influencias? El analizar este tipo de elemento ofrece la mejor posibilidad de penetrar en las circunstancias del traductor- si se quiere, en su mentalidad. Además estas circunstancias nos podrían permitir identificar al traductor. El cotejo de las versiones árabe y castellana ha sido exhaustivo: he comp arado el manuscrito 235 palabra por palabra con el texto canónico del Corán (reproducido en la edición cairota de 1923), y sólo así he podido apreciar la cap acidad del traductor en sus dos vertientes: su conocimiento del árabey su dominio del español.

\section{ANÁLISIS}

Presento en esta sección una serie de ejemplos de giros sintácticos, morfológicos y léxicos, tanto representativos como excepcionales, extraídos de la traducción española. A continuación sacaré algunas conclusiones generales basadas en estos ejemplos.

\section{SINTAXIS}

1. Tiempos verbales. El verbo árabe posee dos aspectos, perfectivo e imperfectivo, que denotan respectivamente acción terminada y no terminada. De ahí que el perfecto árabe pueda representarse en español, según el caso, con el pretérito perfecto, el presente perfecto, o el pluscuamp erfecto antiguo o moderno: kataba 'escribió', 'ha escrito', 'escribiera', 'había escrito'. De la misma manera el imperfecto árabe puede hacer las veces de un presente, un futuro, o un

3. Ver dos libros de H. V. SePHIHA, Le ladino. Judéo-espagnol calque. Deutéronome, versions de Constantinople (1547) et de Ferrara (1553) (Paris: Centre de Recherches Hispaniques, 1973), y Le ladino (judéo-espagnol calque): Structure et évolution d'une langue liturgique, I (Paris: Sorbonne Nouvelle, 1979); y con aplicación a las versiones españolas del Corán, C. LóPEZ-MORILlAs, “Hispano-Semitic Calques and the Context of Translation”, Bulletin of Hispanic Studies, 67 (1990), pp. 111-128. 
pretérito imp erfecto en español: yaktubu ‘escribe’, 'escribirá', 'escribía’. Aunque el sistema es más pobre en tiemp os que el verbo español, el uso de partículas y de alteraciones morfológicas permite crear formas más matizadas, equivalentes a casi todas las españolas: subjuntivo, imp erativo, tiemp os progresivos, condiciones, etc. El que traduce del árabe a una lengua europea puede aprovecharse de esta flexibilidad y falta de fijeza del sistema semítico, pero no puede dejar totalmente de lado el sentido que comunican los aspectos perfectivo e imperfectivo.

Nuestro traductor no siempre presta la atención debida a las variantes temporales del verbo coránico, y comete equivocaciones como las siguientes: ${ }^{4}$

Traducir un perfecto árabe con un presente español:

wa-anzala... mä'an 'ha hecho bajar agua' (2:22): “y deballa... agua” [1 v]

kariha 'no ha aprobado’ (9:46): “esquiba” [107 v]

fa-qāa ‘dijo’ (38:23): “y diçe” [259 v]

En estos ejemplos la alteración del sentido no es significativa. Sin embargo en una frase condicional, el usar presente por perfecto elimina la cualidad irreal de la condición:

law arād $\bar{u} . .$. la-acadd $\bar{u}$ 'si hubieran querido... se habrían preparado' (9:46), construcción que pide un tiempo anterior en español, se traduce por "si quieren... armanse” [107 v].

Traducir un imperfecto con un pretérito: yuhlik ūna 'se pierden' (9:42): “destruy eron” [107 v] yaḥlifūna ‘juran’ (9:74): “juraron” [108 r]

lä yu'minūna 'no creen' (36:7): “no crey eron” [250 r]

Traducir un futuro con un pretérito:

sa-yaḥlifüna ‘jurarán’ (9:42): “juraron” [108 r]

Traducir un perfecto con un imperativo:

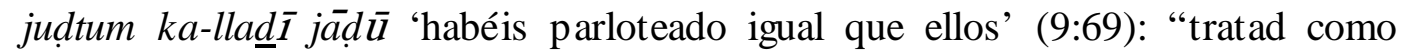
aquelloque trataron" [109 r]

Traducir un imperativo con un pretérito:

wa-ḍrib lahum 'propónles’ (36:13): “y dio a ellos” [250 r]

4. Para facilitar la comprensión, suplo: a) la cita coránica en árabe transliterado (en bastardilla); b) su glosa en español mo derno según la traducción de J. Cortés, El Corán, 5. a ed. (Barcelona: Herder, 1995) (entre comillas simples); c) los números del capítulo o azora (sūra) y del versículo (āya) del Corán, entre paréntesis; d) la lectura del ms. 235 (entre comillas dobles); y e) el número de folio de 235, entre corchetes. 
En juḍtum y wa-ḍrib estamos ante un puro malentendido o falta de atención, pues en estos verbos el imperativo y el perfecto no comparten el mismo patrón consonántico y no deben ser confundibles.

Donde el Corán emplea un sustantivo verbal la traducción puede convertirlo en verbo activo, construcción más natural en una lengua romance:

dálika taqdīru l-cazīzi ‘... por decreto del Poderoso’ (36:38): “aquello lo ordeno... el honrrado" [251 v]

Altraductor se le escapa en ocasiones el matiz de un subjuntivo o condicional, y traduce con un indicativo:

lacallakum tattaqūna 'quizás... tengáis temor’(2:21): “y sereis temerosos” [4 v]

li-yundira man kâna ḥaqqan wa-yahiqqa l-qawlu 'para que advierta a todo vivo y se cumpla la sentencia’ (36:70): “para que pedriques... a quien es creyente. Y adeudeçiose la saña...” [253 r] (No ha visto que yahiqqa también está regido por li, y por tanto está en subjuntivo.)

'afà -llahu canka ‘iQue Dios te perdone!’ (9:43): “dio pasada Allah de ti” [107 v] lacanahum allah ‘ ¿Que Dios les maldiga!’ (9:68): “maldixolos Allah” [109 r] (En los dos últimos ejemplos, no se ha reconocido la cualidad optativa del perfecto.)

En el caso contrario, a veces el que traduce introduce un subjuntivo que no existe en el texto árabe:

fa-hum lā yabșirūna 'de tal modo que no pueden ver’ (36:9): “porque no viesen” [250 r]

yaltaqiyān ‘que se encuentran’ (55:19): “que se encontrasen” [304 v]

2. Voz pasiva/activa. La voz pasiva se distingue de la activa en árabe por una alteración de las vocales internas; puede no haber diferencia en el patrón consonántico. En nuestro texto hay varias discrep ancias con el texto coránico:

Traducir la voz pasiva por la $3^{\text {a }}$ persona plural activa:

q17a lahum 'se les dice’ (2:11, 2:13): “les dezian” [1 r]

ulq $\overline{1}$ ‘... que se... arroje’ (67:8): “lançan” [322 r]

Convertir la voz pasiva en activa:

țubica calà qulübihim 'han sido sellados sus corazones' (9:87): “sello Allah sobre sus coraçones” [110 v]

ḍuriba matalun 'se prop one una parábola' (22:73): “ya os da semblanças” [190 r] wa-law dujilat 'si les hubieran entrado’ (33:14): “Y si dentra sobre ellos /Abu 
Çufyen/” [237 v]. Se ha sup lido un agente del verbo, procedente de tafsīr. lāyus’alu ‘ni... serán interrogados’ (55:39): “no demandara” (futuro) [305 r]. En este pasaje el cambiar a la voz activa acarrea una inversión del sentido: el Día del Juicio la persona no demanda, sino que es demandada por lo que hizo en la vida.

En otros muchos casos, no obstante, se traduce la voz pasiva correctamente:

u'iddat 'ha sido preparado' (2:24): “fue aparejado” [2 r]

kutiba 'alayhi 'se le ha prescrito' (22:4): “es escrito sobrel” [185 v] q17a ‘se dijo' (36:26): “fue dicho” [252 r]

3. Interrogación y negación. Las interrogaciones, introducidas según el caso por las partículas $a$, am y hal, se le pueden escapar al traductor. Es un poco torpe para reconocer las preguntas retóricas, muy típicas del estilo coránico, traduciéndolas a veces en afirmativo (aunque podría tratarse de una elección estilística de su parte):

a-nu'minu '¿Es que vamos a creer...?' (2:13): “no queremos creer” [1 r]

a-laysa -llahu bi-aclama bi-l-šakirinna '¿No conoce Dios mejor que nadie a los agradecidos?' (6:53): “pues Allah es sabidor con los agradeçientes” [71 v] a-tajšūnahum ‘¿Les tenéis miedo...?’ (9:13): “no les ayáis miedo” [105 r] a-nuț 'imu '¿Vamos a dar de comer...?' (36:47): “no queremos dar a comer” [252 r] a-lä yaclamu ‘¿No va a saber...?’ (67:14): “a la fe, el sabe” [322 r]

En otras ocasiones hace caso omiso de la partícula interrogativa, tomando como afirmativas frases como:

hal tarabbașūna ‘¿Qué podéis esperar...?’ (9:52): “no esperan” [108 r] hal kuntu illā bašaran ras ülan '¿Y qué soy yo sino un mortal, un enviado?' (17:93):

"no soy y o sino hombre y mbiado por mensagero" [159 r]

También puede caer en el error contrario, entendiendo interrogación donde no la hay: man kāna yazuunnu ‘Quien crea que...’ (22:15): “¿quien es el que pretende...?” [186r] ittaqū ‘¡Temed...!’ (36:45): “¿por que no temeis...?” [257 r]

Interrogación y negación son susceptibles de confundirse en árabe; p or ejemplo la-, partícula “enérgica” o de afirmación, se puede leer como lā ‘no’. Así le ocurre al traductor en:

innaka la-anta l-ḥalīmu ‘Tú eres, ciertamente, el benigno’ (11:87): “A la fe, no eres tu el paçiente" [126 r]

Tampoco ha reconocido que lammā puede ser combinación de la + mā (partícula negativa), con lo cual hace positivo otro negativo: 


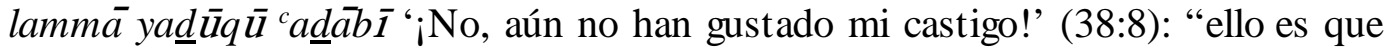
gustaranel al@deb”[258 v]

Las partículas bal y lakin/lakinna 'pero', con sentido adversativo y matiz negativo, las suele interpretar bien (traduciendo 'mas' o 'mas empero'), aunque traduce un bal con 'que', perdiendo así el matiz:

bal alladīna kafar $\bar{u}$ 'Pero los infieles...’ (38:2): “Que aquellos que descreyeron...” [258 v]

La combinación lā... illa ‘no... sino’ es frecuente, tanto que puede surgir en el texto español donde faltaba en el árabe:

anā nadīrun 'Yo soy solamente un monitor' (67:26): “yo no soy sino mensagero” $[322 \mathrm{v}]$

\section{MORFOLOGÍA}

1. Persona. La persona del verbo árabe se sustituye por otra del español en contadas ocasiones:

lam tarawhā 'invisibles [lit. 'no las visteis']' (9:40): “no las vieron” [107 r] (3 $3^{\mathrm{a}} \mathrm{pl}$. en lugar de $2^{\mathrm{a}} \mathrm{pl}$.)

in nacfu... nu'addib 'si perdonamos... castigaremos' (9:66): "si [se] da pasada... sera @debado” [109 r] (3 $3^{\mathrm{a}}$ sg. en lugar de $1^{\mathrm{a}} \mathrm{pl}$.)

fa-in tawallaw 'si te vuelven la espalda' (9:129): “si volbereis las cuestas” $[114 \mathrm{r}]\left(2^{\mathrm{a}}\right.$ pl. en lugar de $3^{\mathrm{a}} \mathrm{pl}$.)

tur ŷy $a^{c}$ üna 'seréis devueltos’ (36:22): “seremos tornados” [250 v] ( $1^{\mathrm{a}} \mathrm{pl}$. en lugar de $2^{\mathrm{a}} \mathrm{pl}$.)

Algunos de estos deslices (como en el primer ejemplo entender *yaraw -por taraw-) podrían exp licarse por una puntuación imp erfecta del texto coránico, que permitiría confundir y $\bar{a}$ ' y tă'; pero otros serían el resultado de inatención o interpretación errónea.

2. Número. No siempre se traduce singular con singular y plural con plural:

li-l-mušrik ina 'los asociadores' (9:7): “al descreyente” [104 v] ŷannä ‘jardines’(9:21, 22:14): “alchannas” [105 v], pero “alchanna” [186 r]

Hay casos en que al traductor se le olvida que en árabe el pronombre - $h \bar{a}$ (lit. '[de] ella'),aunque lleva forma de femenino singular, puede tener referencia a un plural: ýannätin... jăidūna fîă 'Jardines... en los que estarán eternamente' (9:100): “alchannas... y son perdurables en ella” [111 v] 
ruddūhā ‘Traédmelos!’ (al-ṣāfinātu 'los caballos’, 38:33): “¡Tornadlo...!” [260 r]

Los términos árabes que denominan grup os de personas, aunque son (como el español gente) de forma singular, suelen tratarse como plurales:

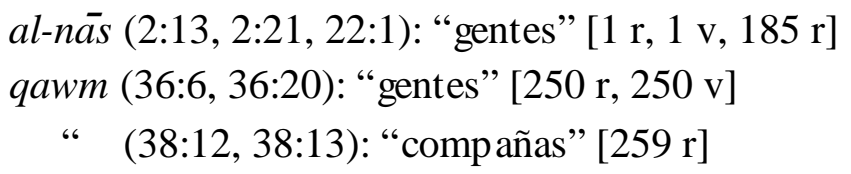

Pero se justifica el plural español donde qawm recibe referencia plural aun en árabe: innakum kuntum qawman fäsiqīna 'ya que sois gente perversa (lit. 'perversos')' (9:53): “porque vosotros sois gentes malas” [108 r]

Otro sinónimo, en cambio, sí se trata como singular: umma 'comunidad' (22:67): “gente” [189 v]

3. Género. Existe algún error provocado por el género del término árabe: yanqalibu ilayka l-bașaru jāsi'an wa-huwa ḥasīrun 'tu mirada volverá a ti cansada, agotada’ (67:4): “volberse a a ti la vista atancada y el cansado” [322 r]

\section{LÉXICO}

Nuestro traductor del Corán demuestra un conocimiento profundo del texto original, cuy o léxico es, como se sabe, vasto y en muchas ocasiones recóndito. Aunque la traducción delata bastantes malentendidos y fallos de comprensión, hay que maravillarse del dominio de su autor tanto del árabe como del español. Evidentemente la consulta de obras de tafsīr en árabe le permitió aclarar muchos pasajes oscuros, pero tales fuentes no le ayudarían a encontrar la palabra española justa; para ello se valió de su propio talento.

En contados casos el traductor intenta variar la exp resión y buscar sinónimos, para no siempre hacer equivaler la misma expresión española a un término árabe: a-lä innahum (2:12): “a la fe, ellos” [1 r]; (2:13): “abisoos que ellos” [1 r] kallā (83:7): “no duden” [338 v]; (83:18): “no dudeis” [338 v]; (83:15): “a la fe” [338 v]

innamā (9:18): “a la fe” [105 v]; (36:11): “mas empero” [250 r $]$ subhāana(hu) (9:31): “tan limpio es” [106 v]; (36:36): “tan vendito es” [253 v ] bal (85:19): “y” [340 r]; (84:22, 85:21): “antes” [339 v, 340 r]

awwab (38:17): “rrep intiente” [259 r]; (38:19): “obidiente” [259 r]

Sin embargo es mucho más frecuente el caso contrario. La riqueza del vocabulario coránico parece agotar la imaginación de su traductor, quien acaba reduciendo dos o más sinónimos árabes a un solo término español: 
a-lä inna (2:13), kallā inna (80:11): “abisoos que” [1 r, $337 \mathrm{r}]$

a-lä(2:12, 9:49), innamā (9:18), a-fa (9:109), balä (36:81, 84:15), kallä bal (83:14):

“a la fe” [1 r, 108 r; 105 v, 112 r; 253 v, 339 v; 338 v]

wa-lammā (9:16), wa-lakinna (22:2), innamā (36:11, 36:82): “mas emp ero” [105 r, $185 \mathrm{v} ; 250$ r, $253 \mathrm{v}]$

hudà (2:120), dīn (2:132), ayät (3:98), sab11 (3:99): “adin” [9 v, $10 \mathrm{v}, 32 \mathrm{r}]$

rabb (1:2), mawlà (9:51), ilah (22:34): “Señor” [iii v, 108 r, 187 v]

ŷund (38:11), ahzab (38:11): “huestes” [259 r]

al-yawm al-ajir (9:18), al-sāca (22:7), yawm al-qiyäma (22:17): “el dia del judiçio”

[105 v, $185 \mathrm{v}, 186 \mathrm{v}]$

in nakațu aymänahum min bac di cahdihim 'si violan sus juramentos después de haber concluido un pacto’ (9:12): “si derruecan sus homenajes despues de sus homenajes” [105 r]

fa-zädathum rîysan ilà riŷsihim wa-mātūwa-hum käfir ūna 'les aumenta la mancha que ya tenían [lit. 'mancha sobre su mancha'] y mueren siendo infieles' (9:125): "hazelos creçer en descrey ençias, y mueren y ellos en la descrey ençia” [113 v]

‘adada l-sinīna wa-l-hisaba ‘contar los años y el tiempo'(17:12): “el quento de los años y el quento” [154 r].

La prosa rimada del Corán tiene en árabe, gracias a sus muchas repeticiones, un efect o auditivo casi hipnótico. Ya que en la prosodia clásica las vocales largas $-\overline{\bar{l}}-\mathrm{y}-\bar{u}$ - forman una rima perfecta, hay miles de versículos que acaban en estos dos sonidos, sobre todo en las sílabas - $\bar{u} n$ e $-\overline{i n},{ }^{5}$ terminaciones del plural de muchos verbos y participios. Al parecer afectado por esta multip licidad de rimas idénticas, nuestro traductor ha tendido a igualar los significados de muchas palabras rimantes. Los verbos “creer” y “descreer” le sirven para todo: siendo frecuente que un versículo acabe en una expresión como in kuntum mu'minīn 'si sois crey entes’ o law ariha l-kāfir ūn 'aunque pese a los descreyentes', el traductor descuida de si la rima en - $\overline{i n} k$ viene, de hecho,del verbo ämana o kafara y traduce con uno de los dos verbos citados. Raíces que se traducen con una forma de “creer” son $h-s-n$ 'obrar bien', $g-f-r$ 'p erdonar', $\underline{d}-k-r$ 'dejarse amonestar', $h-d-y$ 'ser guiado', s- $b-r$ 'tener paciencia', 'c- $q-l$ 'razonar' y $\check{s}-k-r$ 'agradecer'. De la misma manera “descreer” sirve para las raíces $k-b-r$ 'ser altivo', $s-r$ - $f$ 'ser inmoderado', $\hat{y}-h$-l 'ignorar', $z-l-m$ 'ser injusto’, $\check{s}-r-k$ 'ser politeísta’, $f$-s- $q$ 'ser perverso’ y $n$ - $\underline{d}-l$ 'ser advertido’. Son descuidos cometidos por influencia

5. $\quad$ En realidad - $\bar{u} n a$ e -īna, pero la vocal final se suprime ante pausa. 
de la repetición: al traductor le resultó más fácil echar mano de una solución única que pensar en muchas soluciones individuales.

Pero no hay que reprocharle demasiado el buscar uniformidad en su lenguaje. Tal vez la limitación del vocabulario fuera deliberada y tuviera, al menos en parte, un fin didáctico: el usar siempre una sola expresión ayudaría a los lectores a apreciar la consistencia interna del texto coránico. Al fin y al cabo, las distintas palabras para 'el Juicio Final' apuntan todas hacia la misma amenaza; y en cierto modo todos esos altivos, inmoderados, ignorantes, injustos y perversos son descreyentes y merecen el castigo del Altísimo.

Al mismo tiempo el ser consistente a veces le lleva al traductor a eliminar distinciones imp ortantes. El árabe nafs (pl. nufūs, anfus) tiene una variedad de acepciones que incluyen 'alma o espíritu’, ‘persona o individuo’ y ‘propio ser’, entre otros. Su traducción más normal en este manuscrito es 'persona', con sentido reflexivo:

mā yajdac ūna illā anfusahum 'sólo se engañan a sí mismos’ (2:9): “no engañan sino a sus personas” [1 $\mathrm{r}]$

Esta locución es tan frecuente que cuando encuentra el traductor un nafs empleado con otro sentido no lo reconoce:

an... tazhaqa anfusuhum 'que exhalen su último suspiro’ (9:85): “desminuir sus personas” [110 v].

\section{ERRORES DE LECTURA}

En algunos lugares parece que el traductor erró p or simple descuido o prisa en la lectura del texto árabe, confundiendo una letra con otra similar o no fijándose en un signo diacrítico.

De forma consistente lee la Forma III de q-t-l, qätala 'combatir', como si fuera qatala 'matar' (9:13,14,29 [105 r, 106 r] et passim), haciendo caso omiso de la vocal larga. La à no siempre se representa como larga en ortografía y tal vez no se distinguiera bien en el ejemplar del que traducía. Comete el error opuesto al traducir yaqtulūna 'habían dado muerte' (2:61) con "guerreaban" [4 v].

Es posible que al traducir mašìd 'deshabitados' (22:45) como “fuertes” [188 v] haya leído la raíz $\check{s}$ - $y$ - $d$ como š- $d$ - $d$ (o tal vez la palabra precedente, “alcaçares”, le indujo a pensar en “fuertes” como el adjetivo más indicado).

En un versículo algo oscuro que habla de subir al cielo fī-l-asbabi ‘por las cuerdas’ (38:10), traduce “p or sus puerta[s]” [259 r]; el parecido de la sílaba -bab- con bab 'puerta' le confundiría.

Otro error fácil de cometerpor distracción es $a^{c} t a d n a ̄ ~ l a h u m ~ c a d a b a ~ l-s a^{c} \overline{i r}$ 'hemos preparado 
para ellos el castigo del fuego’ (67:5): “contemos para ellos el al@deb de chehannam” [322 r]. La raíz es ${ }^{c}$-t- $d$ (en la Forma IV, $a^{c}$ tada 'prep arar'), pero el traductor ha leído ${ }^{c}-d-d$ 'contar', algunas de cuyas formas conllevan la noción de 'preparar'(incluyendo la VIII, i'tadda, de parecido superficial con $a^{c}$ tada).

He aquí otros posibles errores de lectura, cada uno con su explicación:

hădā šay’un yurādu 'esto es algo deseable' (38:6): “esta es cosa fea” [258 v]. Aquí pudo ser un copista, y no el traductor original, el responsable del desliz. Si el traductor usaba la s larga, la expresión “(cosa que se) desea” podría leerse más adelante, al caer esa $s$ en desuso, como “defea." "Cosa fea” sería entonces la lectio facilior. Hay que atribuir esta interpretación al primer amanuense que pasó la traducción de letras latinas a letras árabes; el copista de 1606 encontraría la fä' ya en su modelo.

qawmu nūhin 'el pueblo de Noé' (38:12): “las compañas de esos” [259 r]. Error explicable sólo si el traductor fue capaz de leer, en el manuscrito del que copiaba, las letras هو como نو constancia no del todo imposible.

ašyācakum 'vuestros semejantes' (54:51): “vuestros antiguos”[304r]. Es posible que leyera la raíz como $\check{s}-y-j$ en lugar de $\check{s}-y{ }^{c}$.

lan yanfacakum al-firāru 'No sacaréis nada con huir' (33:16): “No os aprobechara el Alcoran” [237 v]. Habrá creído el traductor leer, en vez de al-firār, al-furqān?

lasta 'alayhim bi-musayțirin illā man tawallà wa-kafara 'no tienes autoridad sobre ellos. Sin embargo, a quien se desvíe y no crea...' (88:22-23): “no eres sobrellos que los fuerçes /a que crean/. Que el bolber las cuestas y el descreer /todo es ad Allah/” [341 r]. Parece que ha entendido inna en lugar de illa.

a-fa-lam takūnū tacqilūna ‘¿Es que no comprendíais?’ (36:62): “y si fueradeis que tubieradeis seso, /no fueradeis adorantes a el” [252 v]. El traductor ha leído lam como law, y por tanto ha empezado una condición (“si fueradeis...”); luego ha tenido que inventar una apódosis.

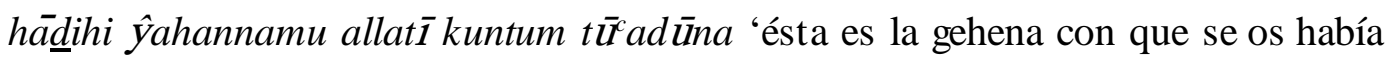
amenazado’ (36:63): “aquesta es chehannam, aquella que eradeis en el mundo /que no crey[a]deis que habia chehannam” [252 v]. Parece que la frase “en el mundo” surgió porque el traductor leyó tī̌cadūna como fī-l-dunyā.

aŷrun kabīr 'una gran recompensa' (67:12): “gualardon honrrado” [322 r]. На 
creído leer karīm (palabra igualmente frecuente en posición de la rima).

\section{ERRORES DE AUDICIÓN}

Hay algún error que parece ser más de audición que de lectura, sugiriendo que en algún momento el traductor trabajó al dictado:

idā tasawwar ū l-mihraba 'cuando subieron a palacio' (38:21): “cuando se figuraron en la mezquida” [259 r]. Las raíces $s-w-r$ 'escalar' y s-w-r 'representar' se distinguen claramente en árabe por su forma gráfica, pero podemos estar aquí ante una pronunciación velarizada de sīn, documentada en el árabe andalusí. ${ }^{6}$ illa man tawallà wa-kafara 'Sin embargo, a quien se desvíe y no crea...' (88:23): “que el bolber las cuestas y el descreer /todo es ad Allah/” [341 r]. Es posible que se entendiera (sin ver el texto) illa' 'excepto' como [lilla] del árabe coloquial (en el clásico li-llahi), 'a Dios’. Sólo esto explicaría la añadidura "/todo es ad Allah/".

\section{ELECCIÓN ENTRE SINÓNIMOS}

Es bien conocida la polisemia de la raíz árabe, por la cual los múltiples derivados de una sola raíz pueden tener significados diferentes y hasta opuestos, para desesperación de todo estudiante de este idioma. En numerosas ocasiones nuestro traductor parece haber escogido, de dos acepciones posibles de una determinada raíz, precisamente la que no es adecuada: ${ }^{7}$

yaz̧har $\bar{u}$ 'alaykum 'os vencen' (9:8): “se asoman sobre vosotros” [104 v]. Z-h-r 'dominar, prevalecer'/ 'ap arecer'.

$\hat{y} a h i d \bar{u} . .$. wa-lam yattajid $\underline{u}$ min düni -llahi... walīyatan 'han combatido sin trabar amistad con nadie fuera de Dios' (9:16): “no mataron a menos de Allah...

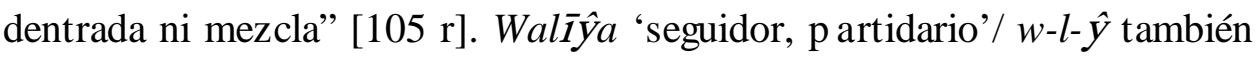
'p enetrar, entrar'.

muṣı̧ba 'una desgracia' (9:50): “tenpesta” [108 r]. Muṣîba 'desgracia'/ ș-w-b también 'caer lluvia, diluviar’.

6. Ver F. CoRriente, A Grammatical Sketch of the Spanish Arabic Dialect Bundle (Madrid: Instituto Hispano-Árabe de Cultura, 1977), pp. 48-49.

7. Al final de cada cita se da la raíz árabe, seguida de a) el significado más indicado en este caso, frente a b) el significado que le da el traductor. 
yafraqūna 'que tiene miedo’ (9:56): “desparten” [108 v]. F-r-q 'temer’/ 'sep arar, distinguir'.

makānan šarqiyyan 'un lugar de Oriente’ (19:16): “em parte resp andeçiente” [169 r]. $\breve{S}-r-q$ 'ir hacia Oriente'/ 'resplandecer'.

bi-aydī safaratin 'por la mano de escribas' (80:15): “en manos de almalaques caminantes” [337 r]. S-f-r 'escribir (un libro)'/ 'viajar'.

¿Por qué tantas veces el traductor parece dudar entre dos sinónimos posibles, para luego elegir mal? Nos recuerda al estudiante de una lengua extranjera que busca un término en el diccionario pero escoge la definición incorrecta. ¿Estaría consultando el traductor algún tipo de glosario? Desde luego, existían en la Edad Media obras de consulta sobre palabras raras o difíciles en el Corán, y por lo menos un traductor del texto al latín parece haberse valido de ellas. ${ }^{8} \mathrm{Y}$ sin embargo si miramos estos mismos pasajes en una de esas obras, Al-mufrädāt fī gar $\not b$ al-qur'ān, ${ }^{9}$ parece difícil que su consulta llevara a las equivocaciones en que cae nuestro traductor. Se distingue claramente entre una y otra definición de cada término, apoyando a veces las definiciones en citas de poesía o de otros pasajes coránicos. Es más, para tres de las raíces equívocas arriba citadas se exp lica precisamente el verso del Corán del que es cuestión aquí. Para los safaratin de 80:15, por ejemplo, se especifica que "son los ángeles descritos en Su dicho 'nobles escribientes' [Cor. 82:11]." ${ }^{10}$ Parece difícil que un buen conocedor del árabe como nuestro traductor no cayera en la cuenta de que los ángeles no caminaban, sino que escribían. Tengo que reconocer que no entiendo por qué el traductor ha cometido varias veces este tipo de error.

\section{VOCABULARIO HISPÁNICO Y CRISTIANO}

Podemos sospechar que ciertas locuciones le vinieron a la mente del traductor por su condición de musulmán español, formado en el ambiente cultural de la Península:

bi-dīnärin 'un dinar' (3:75): “con doblas” [30 r]

maŷla 'refugio' (9:57): “castillo” [108 v]. ¿Qué refugio más seguro, para un nativo de Castilla, que un castillo?

‘aŷamiyyun ‘una lengua no árabe’ (16:103): “rromançe” [151 v]. La 'lengua no-árabe’ por antonomasia para este traductor.

8. T. E. BuRMAn, “Tafs İr and Translation: Traditional Arabic Qur’ än Exegesis and the Latin Qur'äns of Robert of Ketton and Mark of Toledo”, Speculum, 73 (1998), pp. 703-732, esp. p. 728.

9. De al-Rāgib al-Iṣbahānī (m. 1108), ed. Muḥammad Aḥmad Kalāf Allah, 2 v. (El Cairo: s.f.).

10. Fa-huwa l-mal äikatu al-mawș ūfūna bi-qawlihi kir äman kätibìna; I, 342. 
dar $\overline{1}^{c}$ 'dari [en nota: 'planta espinosa y amarga del desierto']' (88:4): “xabroc/y en latin se llama y xola/” [341 r]. Se trata de una planta también llamada šibriq; la glosa con el nombre latino tiene que proceder de una fuente hispánica o andalusí.

Es más, el traductor se muestra en ocasiones buen conocedor del vocabulario cristiano:

wa-antum 'akifūna 'mientras estéis de retiro' (2:187): "hiziendo nobenarios”[15 r] lā taqūl tu talatâtatun ‘¡No digáis “Tres”!’ (4:171): “no digais ‘Nuestro Señor es trino’” [55 r]

rūḥi l-qudusi ‘el Espíritu Santo’ (lit. ‘el espíritu de santidad’) (2:87, 2:253, 5:110): “espiritu san(c)to” [6 v, 21 r, 66 v].

\section{ERRORES SIN EXPLICACIÓN}

Quedan por citar errores de traducción para los que no encuentro justificación razonable. En éstos, el traductor sencillamente no ha comprendido lo que leía y ha producido una versión incoherente, a veces hasta contraria al sentido del original:

lā tajūnū -llaha wa-l-rasūla wa-tajūnū amānātikum '¡No traicionéis a Dios y al Enviado! ¡No traicionéis... la confianza puesta en vosotros!' (8: 27): “no hagais malbestades ad Allah y al mensajero -y hizisteis malbestad” [100 r]. No ha visto el traductor que la partícula lā, aunque no se repite, rige ambos verbos, y ha convertido un imperativo negativo (el segundo tajünü) en indicativo. Ha hecho caso omiso de amānātikum.

$w a^{c}$ dan 'alayhi ‘Es una promesa que Le obliga' (9:111): "fue prometida el alchanna sobrel” [112 v]. El traductor supone que 'el' es el hombre, o el Profeta, cuando de veras se trata de una promesa que le incumbe cumplir a Alá. al-wașīd 'el umbral [de la cueva]' (18:18): “el desierto de la cueba” [161 r]. tad halu kullu murḍicatin 'ammā arḍacat 'toda nodriza olvidará a su lactante' (22:2): "demandaran a todo mamador por lo que mamo" [185r]. Se le han escap ado al traductor las desinencias femeninas del sustantivo (-at-) y del verbo (ta-, -at), con lo cual toma por sujeto al lactante.

nādà rabbuka mūsà ‘tu Señor llamó a Moisés’ (26:10): “vino tu Señor [a Muçe]” [205 v]. Sin motivo ap arente.

lā yahțimunnakum sulaymānu wa-ŷunüduhu wa-hum lā yašcurūna ' $i$...no sea que Salomón y sus tropas os aplasten [a las hormigas] sin darse cuenta!' (27:18): 
"que no os tronçe Çuleymen y sus huestes. Y ellos no sabian /que Çuleymen entendia su habla dellas/" [212 r]. Se trata de no reconocer un wāw al-hal (wa-hum la....); así queda colgando la oración “y ellos no sabian.” Aunque los que no saben son las huestes, el traductor sup one que son las hormigas (a pesar del masculino "los") y tiene que suplir un comentario explicativo.

aḥbabtu hubba l-jayri 'an dikri rabbī 'Por amor a los bienes he descuidado el recuerdo de mi Señor’ (38:32): “y o e yvantallado amar el bien... y no çesare del nombramiento de mi Señor” [260 r]. El traductor no ha comprendido esta connotación de la preposición 'an , 'en lugar de’. Su “no çesare” es pura invención.

yad' ūna... bi-fäkihatin 'pedirán fruta' (38:51): “serán viçiosos... con frutas” [260 v]. lammā qāma cabdu -llahi yad'ühu 'Cuando el siervo de Dios se levantó para invocarle' (72:19): "son almacam del sierbo de Allah... que rruega ad Allah" [328 v]. Al p arecer por falta de atención, se ha convertido el adverbio + verbo lammā qāma en un supuesto sustantivo "almacam".

\section{EL PAPEL DE LOS COMENTARIOS}

Analizados la sintaxis, la morfología y el léxico de la obra de nuestro traductor, se imp one un hecho fundamental: no se puede entender cómo entendió y romanceó el Corán árabe sin tomar en cuenta los comentarios árabes al texto sagrado, es decir el género tafsīr. En el ms. 235 los comentarios exegéticos están diferenciados del texto coránico, bien por estar escritos en tinta roja, bien por aparecer entre barras diagonales (//). Esta distinción clara entre Corán y tafsīr ha hecho pensar -a mí y a otros-que todo comentario adicional está identificado como tal, y que si se le restaran al manuscrito estos pasajes quedaría una versión pura del Corán árabe que merecería verdaderamente el nombre de "traducción”. En esto se distinguiría el 235 de los muchos manuscritos que contienen versiones parciales del Corán en aljamiado, las cuales, no manifestando semejante distinción, serían comentarios u obras de tafsīr pero no traducciones propiamente dichas ${ }^{11}$ Esta impresión es, sin embargo, falsa. Luego de cotejarlo minuciosamente con el Corán, veo que el ms. 235 se vale de una exégesis "oculta” que no aparece identificada ni con tinta roja ni con barras, sino que está absorbida dentro de la traducción misma y reflejada en la selección léxica que ha hecho el traductor, selección que en gran número de casos produce no una traducción, sino una

11. P. VAn KoningSveld, en su reseña de mi libro The Qur'ān... en Al-Arabiyya, 17 (1984), pp. 135-141, insistió sobre este punto. Ver también WIEGERS, Islamic Literature..., pp. 106-114. 
interpretación del texto coránico. ${ }^{12}$ Una y otra vez, al leer en el texto español lo que parecía ser una versión inexacta del original árabe, he encontrado su motivación en el tafsīr. Como muestra preliminar, presento los siguientes ejemplos: ${ }^{13}$

al-nasi’u 'el mes intercalar’ (9:37): “el açaguear” [107 r]. Z 2:189: ta'jīru hurmatal-šahri ilă šahrin äjirin 'el aplazar la inviolabilidad del mes hasta otro mes.'

wa-fikum sammā $\overline{a^{c}}$ na 'Hay entre vosotros quienes dan oídos a...' (9:47): “disfamando a ellos” [107 v]. Sammaca significa tanto 'hacerle a alguien oir' (significado que recoge Cortés) como ‘disfamar' (el que prefiere 235). Z 2:194: nammāmūna yasma'ūna hadîtakum fa-yanqulūnahu ilayhim 'calumniadores que escuchan vuestras nuevas y se las transmiten a ellos.'

ištacala l-ra'su šayban 'mis cabellos han encanecido’ (19:4): “se a ençendido la cabeça de canas” [168 v]. Š-c-l vale tanto 'tener un mechón blanco' como 'encender.' Z 2:502: šabiha l-šaybu bi-šuwāẓi l-nāri fībayạ̄̂hihi wa-ināratihi wa-intišārihi fī-l-ša $a^{c} r i$ 'las canas se parecen a la llama del fuego por su blancura, su iluminación y su extenderse entre los cabellos.’

wa-nas ūqul-mu ŷrimīna... wirdan 'y conduzcamos a los pecadores en masa' (19:86): “y traeremos a los descreyentes... asetados” [172 v]. W-r-d significa 'llegar una compañía o tropel al agua.’ La idea de la sed se encuentra en Z 2:524: wa-dukiral-käfir ūnabi-annahum yusāqūna ilà l-nāri bi-ihānatin wa-stijfäfin ka-annahum nacamun 'itã̌un tusāqu ilà l-mā' $i$ 'y se dice de los descrey entes que son llevados a beber al fuego con desp recio, como si fueran bestias sedientas conducidas al agua.'

tumma la-yaqtac ' 'luego la corte [la cuerda que llega al cielo]' (22:15): “despues

12. T. E. BuRman, en “Tafs $\overline{\mathbf{I}}$ and Translation...”, ha demostrado que la traducción latina de Roberto de Ketton, muchas veces tachada (por Juan de Segovia, entre otros) de incorrecta y parafraseada, en realidad incorpora exégesis árabe sin mencionarlo, de forma exactamente análoga a lo que aquí ilustro.

13. Como he dicho al principio, el uso de tafs $\overline{I r}$ en este texto es un tema amplísimo que estudiaré a fondo en otra ocasión. Para este artículo he consultado uno de los comentarios más leídos y al que podría haber tenido acceso Yça Gidelli, el de Zamajšarī: Abū l-Qāsim Ŷ̄ārallah Maḥmūd b. ' U mar al-Zamajšarī al-Jwarizmī, Al-Kaššăf

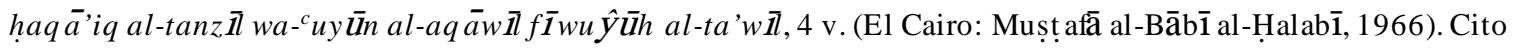
con la inicial “ Z” seguida del número del tomo y de la página. 
ahoguese hasta que muera” [186 r]. Z 3:8: wa-summiya l-ijtināqu qațan li-anna l-ijtināqa yaqtacu nafsahu bi-ḥabsi ma ŷăhi wa-minhu qila li-l-buhri $a l-q a t^{t} u$ 'y al ahorcamiento se le llama "corte", porque el ahorcamiento le corta a uno con un impedimento en el flujo [del aire], y de ahí que la falta de aliento se llame "corte".'

wa-mā arsalnā... min rasūlin... illā id $a^{-}$tamannà alqà l-šaytānu fī umniyatihi 'Cuando mandábamos... a algún enviado... siempre enturbiaba el Demonio sus deseos' (22:52): "Y no ymbiemos... mensagero... que no fuese que quando leya se lançaba el axeyttan en su leer” [188 v-189 r]. Z 3:19: wa-umniyatihi qirä'atihi 'y sus deseos son su lectura.'

dikrun li-l-calamina 'una amonestación dirigida a todo el mundo' (38:87): "rremembrança para los nigligentes de las gentes" [261 v]. Z 3:385: li-l-taqqàīna 'a los torpes.'

yawma hum bārizūna 'ese día surgirán'(40:16): “el dia que seran desentos” [267 v]. Sólo se comprende "desentos” si implica "desprovistos de ropa”, según Z

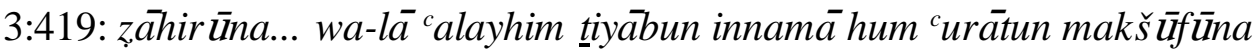
'aparecen... no llevando encima vestidos; están desnudos, destapados.'

fa-hum yūzac üna 'serán divididos en grupos' (41:19): "ellos se yran deteniendo"

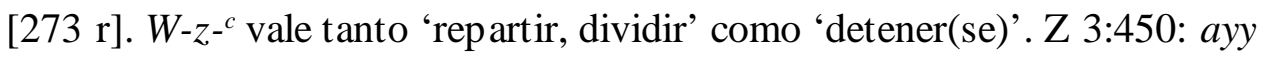
yuhbbasu awwaluhum 'alà ajirihim, ayy yustawqafu sawabiquhum 'es decir, son confinados los primeros de ellos con los otros, o se para su avance.'

li-ayyi yawmin uŷyilat li-yawmi l-fașli ‘¿Qué día comparecerán [lit. '¿Hasta qué día se ha aplazado?’]? ¡El día del Fallo!’ (77:12-13): “para la grandeça y marabilla de aquel dia” [334 r]. Z 4:203: tac żimun li-l-yawmi wa-tac $\hat{y} \bar{l} b u n$ min hawlihi ‘la grandeza del día y la maravilla de su espanto.'

En ninguno de estos pasajes hay indicación en el manuscrito, en la forma acostumbrada de barras separadoras, de que se está incluyendo una interpretación extracoránica. Se trata de una introducción de materia exegética totalmente ex silentio.

\section{OBSERVACIONES GENERALES}

Con los detalles arriba expuestos, estamos en condiciones de especular si su autor original pudo haber sido, como se ha propuesto, el alfaquí de Segovia Yça Gidelli. 
Gracias al prólogo latino de Juan de Segovia, ${ }^{14}$ extraordinariamente pormenorizado al describir el proyecto de la traducción, sabemos cómo trabajaba Yça y qué medios tenía a su disposición. Llegó a Aiton en diciembre de 1455 y dedicó cuatro meses a la empresa. Cuatro meses es poco tiemp o si se considera que no sólo tradujo el texto sagrado sino que a la vez lo copió íntegro, para dejarle a Juan una versión bilingüe. (El amanuense del 235 en 1606, quien sólo sacó una copia de una traducción ya existente, tardó unos tres meses en completarla.) En el primer mes el alfaquí escribió el texto árabe, en el segundo lo vocalizó, en el tercero lo tradujo y en el cuarto lo corrigió, trabajando al menos doce horas al día y hasta levantándose a veces de noche cuando se le ocurría algo que apuntar. Como estaba Yça recién casado y deseoso de volver a Segovia, se tuvo que encontrar otro escribidor para hacer la copia -sólo del texto español- que aquél se llevaría consigo.

Aunque la traducción en general es admirable, he señalado un número bastante elevado de errores que delatan una falta de atención a los detalles: malas lecturas, equivocación en los tiempos verbales, y reducción de un léxico muy rico a otro limitado. Otros lapsus atribuibles a la falta de tiemp o son las muchas omisiones: diez veces se omite un versículo entero, y nada menos que 38 veces un fragmento de versículo. ${ }^{15}$ Por lo tanto, el texto que conocemos podría ser producto del apresuramiento que sintió Yça Gidelli durante su preparación.

Sabemos también que Yça se llevó con él a Saboya, y utilizó para su traducción, obras de tafs īr o exégesis en árabe. Juan de Segovia observó que cuando Yça dudaba, consultaba “muchos... libros escritos sin vocales” que decía ser de expositores del Corán. ${ }^{16}$ Y nos dice el mismo Yça en la introducción al Breviario çunni que escribió varios años después: "plugo a la ynmensa piadad...tiniendo el atasçir delante... fuese [el Corán] romançado”. ${ }^{17}$ Hemos visto que las obras de tafs îr explican muchas peculiaridades de la traducción; es otro dato que puede identificar a ese traductor con Yça de Segovia. Aunque Juan no dice explícitamente que Yça consultó un glosario de voces difíciles, es posible que éste figurara también entre las fuentes árabes de que se valió el alfaquí.

14. Reproducido en D. CABANELAS RodRíGuEZ, Juan de Segovia y el problema islámico (Madrid: Universidad, 1952), pp. 279-302.

15. Es verdad que las omisiones igualmente podrían atribuirse al copista de 1606; pero aunque sólo la mitad fueran culpa del traductor, serían muchas.

16. "Vidi... quod multos haberet libros scriptos absque vocalibus”. Cabanelas, Juan de Segovia..., p. 299.

17. Son lecturas combinadas de dos mss.; la referencia al “atasçir” ocurre sólo en uno. WIEGERS, Islamic literature..., p. 237. 
Hay una práctica más que me sugiere que lo que contiene el ms. 235 es la traducción de Yça: la división de la obra en cuartos. El índice de las azoras del Corán ocupa las cuatro primeras hojas del manuscrito. En este índice figuran en cada línea el número del capítulo, su título (p. ej., "El açora de alhamdu lillehi”), y, al final del renglón, el número del folio en que empieza. ${ }^{18}$ Pero además, unos apuntes marginales (en la misma letra) marcan otro tipo de división, no canónica: dónde acaba cada cuarta parte del libro. Al lado de los renglones para las azoras 6 y 7, se señala: “aqui es fin un quarto”; al lado de los renglones 18 y 19, “aqui es fin dos quartos”; y al lado de los renglones 37 y 38 en la hoja siguiente, “aqui es fin tres quartos”. (El último “quarto” no se marca, por corresponder lógicamente al final del texto.) Si consultamos el manuscrito en los lugares indicados encontramos que, en efecto, en esos cuatro puntos el amanuense ha hecho una pausa en su labor y ha escrito una especie de colofón: estos párrafos vienen al final de las azoras 6, 18, 37 y 114 (fols. 81 v-82 r, 167 r, 258 r y 347 v, respectivamente). ${ }^{19}$ Ahora bien, mantiene Juan de Segovia en su prólogo latino que los musulmanes habían dividido su escritura en cuatro libros, "así como los Evangelios son cuatro.” ${ }^{20}$ Esta información tuvo que recibirla del mismo Yça Gidelli, pues viene de la tradición musulmana: por ejemplo Ibn Ab̄̄ Da’ūd, en Kitab al-Maṣaḥif, cita una tradición de al-Haŷŷŷy ibn Yūsuf según la cual el primer cuarto del Corán acababa con Sürat al-añàm (no. 6), el segundo con S. al-kahf (no. 18), y el tercero con S. al-zumar (n' ${ }^{\circ}$ 39). ${ }^{21}$ Son casi las mismas divisiones que se hacen en el ms. 235 (salvo que en éste último, el tercer corte ocurre dos capítulos antes).22 Si Juan de Segovia conocía esta práctica, tuvo que ser porque Yça se la había enseñado y la había hecho constar en su traducción del Corán al castellano en 1456. La división en cuatro secciones que encontramos en el ms. 235 sería, pues, un elemento introducido por Yça y conservado en copias intermedias (hoy desconocidas) hasta que reapareció en 1606.

Un pequeño detalle adicional hace pensar en una conexión entre el ms. 235 e Yça Gidelli. El nombre de la moneda árabe dīnarr, en la expresión coránica bi-dīnärin 'con un dinar' (3:75), se traduce en el manuscrito “con doblas” [30 r]. No he podido averiguar si ésta era una traducción

18. Solamente para las primeras cuatro azoras, se apunta también el número de versículos o àa $\bar{a}$ que contienen.

19. Los colofones se han reproducido y estudiado en LóPEZ-MORILLAS, “ Trilingual Marginal Notes...”.

20. “ “sicut Evangelia sunt quatuor”: CABANELAS, Juan de Segovia, p. 293.

21. Bobzin, “Bemerkungen...”, p. 542. La noción de las cuatro partes del Corán aparece también en el libro del converso Juan Andrés y en escritores cristianos del s. XVI que lo utilizaron como fuente.

22. Según Bobzin, “ Bemerkungen...”, p. 543, diversos autores árabes sitúan en puntos diferentes el final del tercer cuarto del Corán. 
convencional en el siglo XV, pero el propio Yça había empleado el término. En una carta a Juan de Segovia, el alfaquí le recordó el sueldo de veinte doblas que le había pedido por su labor de traducción: “...et licet ego petivi eo finaliter postremum pretium viginti duplas pro solo labore meo..... ${ }^{23}$

\section{CONCLUSIÓN}

Este análisis de la traducción española del Corán contenida en el manuscrito de 1606 -fragmento de una edición y estudio completos- ha tenido dos fines: ilustrar los métodos y los conocimientos del traductor, y tratar de averiguar si éste pudo ser el alfaquí Yça Gidelli.

Está claro que el traductor conocía muy bien las dos lenguas en cuestión y que poseía un conocimiento profundo de la sagrada escritura islámica. Dependió de obras de tafsīr en árabe hasta tal punto que llegó a parafrasear el texto coránico para incluir interp retaciones de los comentaristas. Trabajó con prisa, lo que le obligó a simp lificar el vocabulario y a cometer errores de interp retación o de omisión; sin embargo, produjo una traducción admirable y digna de servir como guía emblemática para las comunidades mudéjar y morisca.

Existen varias pistas sugestivas que ap untan hacia Yça, el traductor de 1456, como autor del texto que conocemos sólo a través del manuscrito de Toledo, escrito en 1606. Entre ellas figuran la incorporación de material exegético al que sabemos que Yça tenía acceso, y la división del Corán en cuatro partes iguales. Pero seguimos careciendo de manuscrito intermedio alguno -sobre todo uno aljamiado- que conecte la versión desaparecida del segoviano con la de 1606. Me extraña que la obra maestra de una figura tan admirada como Yça Gidelli no dejara huella en su país natal durante siglo y medio, y que el copista de 1606 ignorara o silenciara el origen del Corán hispánico que tenía delante. Sigo, sin embargo, con la esperanza de poder confirmar un día de forma convincente la relación directa entre los dos textos.

\section{RESUMEN}

El manuscrito 235 de la Biblioteca de Castilla-La Mancha (Toledo), de origen morisco y fechado en 1606, contiene una traducción completa del Corán del árabe al español. Ya se había sugerido que representa la única versión conocida de la traducción hecha por 'Īsā b. Ŷābir ("Yça Gidelli”) en 1456 y dada por perdida. El presente artículo, parte de la introducción a una primera edición del manuscrito, estudia cómo trabajó el traductor y analiza el lenguaje de la versión española en comparación con el original árabe. Revela que el traductor incorporó a su versión muchas

23. D. CABANELAS, Juan de Segovia..., p. 274. 
interp retaciones que sólo pueden derivar de obras de tafs $\bar{\imath}$, pero sin señalar su origen. Aporta también nuevos datos que ap oy an -aunque no confirman- la identificación de Yça Gidelli como el traductor.

\section{ABSTRACT}

Manuscript 235 of the Biblioteca de Castilla-La Mancha (Toledo), of Morisco origin and dated 1606, contains a complete translation of the Qur'ān from Arabic into Spanish. It had already beenprop osed that this manuscrip trep resents theonly known version of the translation made by cīs $\bar{a}$ ibn Ŷābir ("Yça Gidelli”) in 1456, previously considered lost. The present article, part of the introduction to a first edition of the manuscript, studies how the translator worked and analyzes the language of the Spanish version as compared to the Arabic original. It demonstrates that the translator incorp orated into his versionmany interpretations that can only comefrom works of tafs $\overline{i r}$, but without identifying their source. It also supplies new evidence that supports -though it does not confirm- the identification of Yça Gidelli as the translator. 